\title{
Thermal Shock Cracks in Work Rolls of Cold Strip Mills*
}

\author{
By Kiyozo SAKABE** and Hirosuke TABE**
}

\section{Synopsis}

The troubles such as slipping, pinching, and crumpling in the operation of cold mills often induce thermal shock cracks on the surface of rolls, especially on work rolls, and considerably reduce their service lives.

A thermal shock testing device utilizing friction heat caused by a rotary disc contacting with test specimens was developed to perform the investigation of thermal shock cracks and a method of quantitative measurement was established to evaluate roll materials by a quantitative determination of some factors that govern the formation of thermal shock cracks in test specimens.

It was proved that $\mathrm{Cr}-\mathrm{Mo}$ steel with 3 to $5 \% \mathrm{Cr}$ was superior to ordinary ones of lower chromium contents, and as the result in actual mill service, it was confirmed that the rolls of 3 to $5 \% \mathrm{Cr}-\mathrm{Mo}$ steels had a very much improved service life.

\section{Introduction}

In recent years cold rolling mills, as a trend, are becoming bigger in size and are operated at a higher rolling speed than before, and this results in an increase of rolling troubles ${ }^{1-4)}$ such as slipping between strip and rolls, breaking of strip, pinching, and crumpling between rolls. The rolling troubles are very likely to inflict an abnormal friction with a local excessive pressure on the surface of a roll and produce an exothermic phenomenon leading to thermal shock cracking; it has been a subject of research of late years to make a work roll having the resistance to the formation of cracks on the roll surface, namely, what is called a crack resisting roll.

The thermal shock cracking is similar in nature to the phenomenon which has been known well as grinding cracking or temper cracking, several facts on its mechanism have been disclosed empirically, and the countermeasures have been taken. ${ }^{5-11)}$

The studies made so far on thermal shock cracks were based on a qualitative judgement, on the surface, of whether a crack was produced or not when thermal shock had been given under a certain condition; thermal shock cracks, however, actually occur in a three-dimensional way ranging from surface to a certain depth. The service life of a cold mill work roll, in particular, fully depends on its hardened layer which lies in the range from the surface till the depth of no more than 12 to $15 \mathrm{~mm}$. So it will be much more significant to perform a quantitative comparison study on the depth of cracks rather than to investigate the size or number of surface cracks. Accordingly, it is prerequisite for the research on the thermal shock property of a roll to establish a test method most appropriate for the above purpose and the evaluation of the test results.
Described in this report is an outline of a research which was made to develop a new roll material having a good resistance to the cracking, and also is given an introduction of a thermal shock testing device. This device was made to reproduce in a small test specimen as truly as possible a thermal shock of the nature that would occur in the rolls and was capable of inflicting friction heat abruptly and locally on the limited surface of test specimen by way of making it contact with a rotary disc. ${ }^{12}$ ) This report refers further to some relations between such conditions as materials and heat treatment and the thermal shock cracks. A number of crack resisting rolls have hitherto been manufactured by making use of the results and findings of this research and the rolling performance of these rolls are mentioned in this report.

\section{Thermal Shock Crack in the Surface of a Roll and the Thermal Shock Testing Device}

\section{Thermal Shock Crack in the Roll Surface}

Photographs 1 (a) and (b) are examples of thermal shock cracks appearing on cold mill work rolls, and the former shows a failure due to pinching in rolling

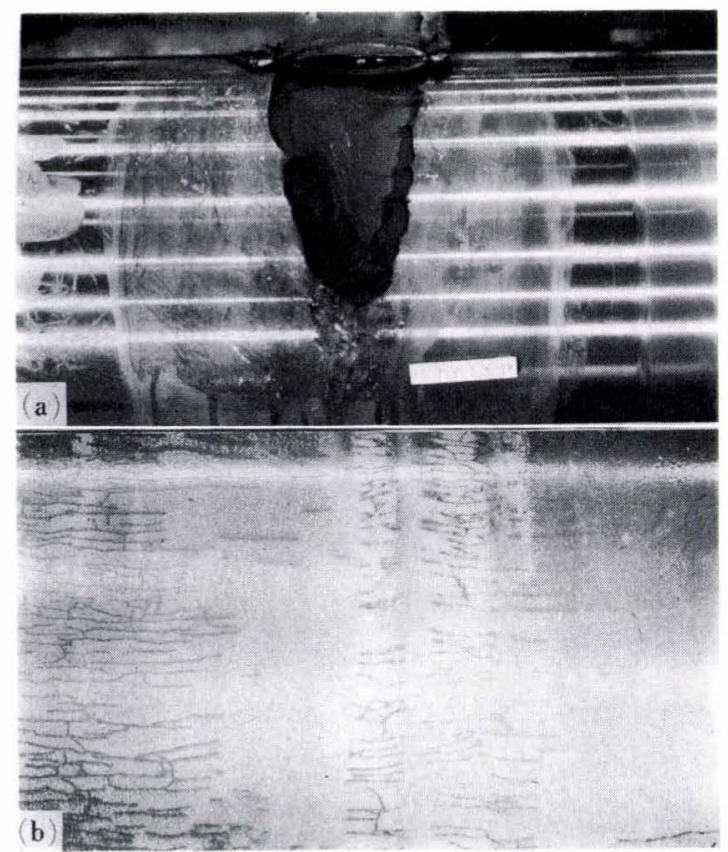

(a) By pinching (b) By slipping of cold work roll Photo. 1. Typical thermal shock cracks in roll surfaces

* Originally published in Tetsu-to-Hagané, 57 (1971), 836, in Japanese. English version received June 19, 1972.

** The Japan Steel Works, Ltd., Yuraku-cho, Chiyoda-ku, Tokyo 100. 
of steel strip while the latter is the cracks caused by slipping in rolling of non-ferrous material. Whether the rolled material is steel or non-ferrous, the cracks have occurred under a certain rolling condition, although the degree of failure may differ. ${ }^{1-3,13,14)}$ Generally the material of these rolls is a eutectoid steel containing $\mathrm{l}$ to $2 \% \mathrm{Cr}$ and hardened by water quenching, and the surface layer consists of almost perfect martensite, the hardness being above $\mathrm{Hs} 90$ in actual mill application. Therefore, the size of cracks changes according to the local heat amount and temperature having occurred in the roll surface during the pinching or slipping and either of a re-hardened layer, an imperfect re-hardened layer or a tempered layer is produced locally or on the whole surface.

\section{Thermal Shock Testing Device}

When the process of cracking due to thermal shock is to be reproduced, it is necessary to have a roll material undergo a rapid heating and rapid cooling. For this purpose, a number of methods as to use high frequency heating, ${ }^{15}$ ) flame heating, direct electric heating, ${ }^{11}$ ) or molten metal ${ }^{2,16,17)}$ have been tried. There is also a method using friction heat. Since the thermal shock crack appearing in the surface of a roll is caused by an excessive pressure inflicted on the roll surface accompanying friction heat, it is considered preferable to take up a method using the friction heat when an improvement of an actual roll material is intended. For this reason, the thermal shock testing device $^{12)}$ was provided with such a setup as illustrated in Fig. 1 where the friction heat caused by having a test specimen in contact with a rotary disc is utilized.

In Fig. 1, the part marked 3 is the rotary disc and 7 denotes the test specimen to be rubbed by the disc. The specimen is set on the cantilever 4 with the fixing block 8 so that the specimen may not move or may not be subjected to a bending stress during test. One end of the cantilever is designed to have a weight up to $60 \mathrm{~kg}$, and it is so contrived that when a $60 \mathrm{~kg}$ weight is set the specimen may exert a pressure of about $350 \mathrm{~kg}$ on the disc. The rotary disc, $550 \mathrm{~mm}$ in diameter and $60 \mathrm{~mm}$ in width, is made of a $0.08 \%$ carbon mild steel similar to ordinary strips. The specimen has the

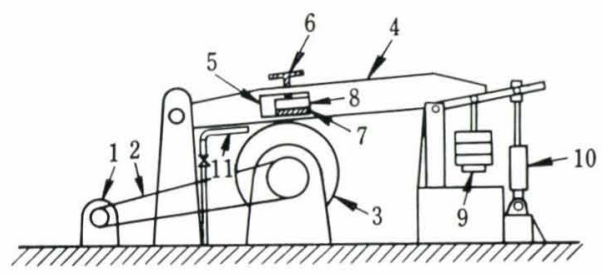
(1) Electric motor
(7) Specimen
(2) Belt
(8) Fixing block for
(3) Rotating disc
(4) Cantilever specimen
(5) Setting slit for specimen
(9) Weight
(10) Oil lifter
(6) Fixing handle for specimen
(11) Coolant spray

Fig. 1. Schematic figure of thermal shock testing device dimension of $80 \mathrm{~mm}$ long and $60 \mathrm{~mm}$ wide with the thickness varying up to $50 \mathrm{~mm}$, so that a variety of roll materials can be tested easily on the device. The part 10 is the oil-hydraulic lifter, whose function is to keep a certain distance so that the disc and the specimen may not contact with each other until the disc reaches to its specified speed of $1055 \mathrm{rpm}$, at which speed a load is given momentarily by a clutchoff mechanism. While charging the load, cooling water is sprayed by the coolant spray 11 on the surface of the specimen with the disc in the same way as in the case of real rolling operation.

In this test the heat amount per unit time produced by friction, the maximum temperature, heat distribution, thermal strain, etc. have not been entirely clarified in a strict sense. It may be said that this test has not gone so far above the level of a comparative test on an industrial scale. However, as the result of investigating such different testing conditions of crack formation as mentioned later, a standard testing condition has been established so that tests may be performed under the same condition. It is believed consequently that it has been made really possible to perform a quantitative comparison test.

\section{Thermal Shock Cracks Produced by the Testing De- vice}

Photograph 2 shows an example of thermal shock crack produced by the testing device. The test specimen shown in Photo. 2 is the one of $2 \% \mathrm{Cr}-\mathrm{Mo}$ steel

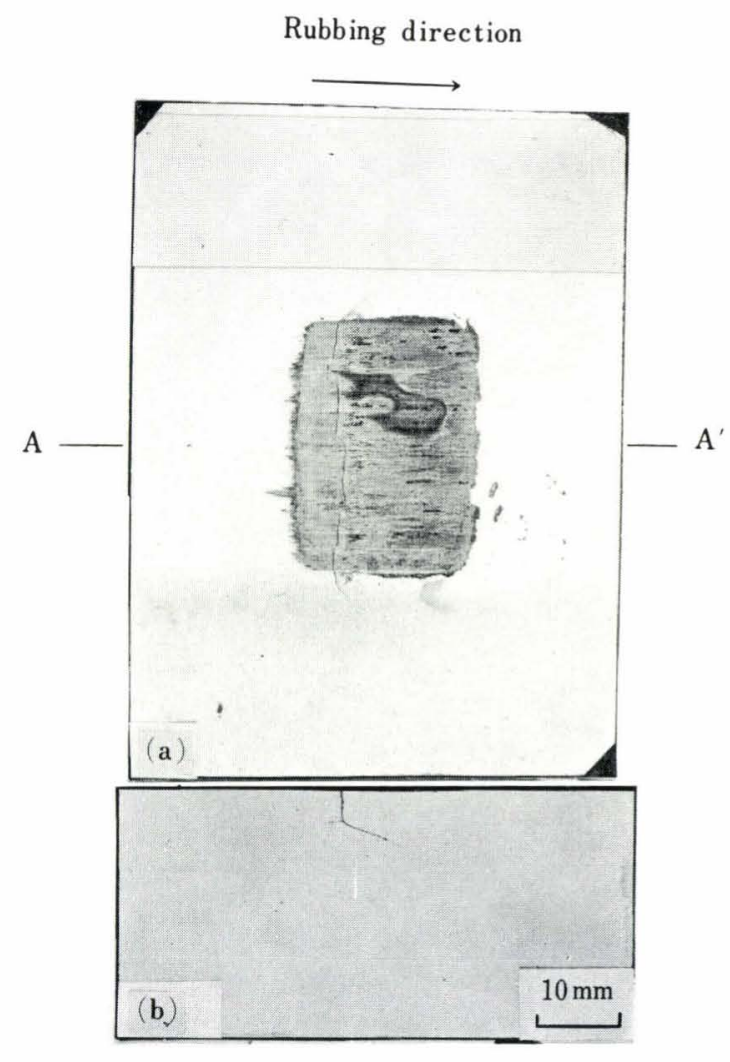

(a) Rubbed surface (b) Center section (A-A' section)

Photo. 2. An example of thermal shock crack appeared on $2 \% \mathrm{Cr}-\mathrm{Mo}$ steel specimen 
Table 1. Materials tested

\begin{tabular}{|c|c|c|c|c|c|c|c|c|c|c|c|}
\hline \multirow{2}{*}{ Material } & \multicolumn{9}{|c|}{ Chemical composition (\%) } & \multirow{2}{*}{ Standard pre-treatment } & \multirow{2}{*}{$\begin{array}{c}\text { Standard } \\
\text { quenching tempering }\end{array}$} \\
\hline & $\mathrm{C}$ & $\mathrm{Si}$ & Mn & $\mathrm{P}$ & $\mathrm{S}$ & $\mathrm{Cr}$ & Mo & $\mathrm{V}$ & Co & & \\
\hline $2 \% \mathrm{Cr}-\mathrm{Mo}$ steel & 0.79 & 0.32 & 0.34 & 0.018 & 0.009 & 2.20 & 0.34 & - & - & Forged \& spheroidized & $\begin{array}{l}860^{\circ} \mathrm{C} \times 1 \mathrm{hr} \rightarrow \mathrm{Oil}, \\
150^{\circ} \mathrm{C} \times 5 \mathrm{hr} \rightarrow \mathrm{FC}\end{array}$ \\
\hline $3 \% \mathrm{Cr}-\mathrm{Mo}$ steel & 0.92 & 0.58 & 0.32 & 0.012 & 0.007 & 2.96 & 0.30 & - & - & Forged \& spheroidized & $\begin{array}{l}860^{\circ} \mathrm{C} \times 1 \mathrm{hr} \rightarrow \mathrm{Oil}, \\
150^{\circ} \mathrm{C} \times 5 \mathrm{hr} \rightarrow \mathrm{FC}\end{array}$ \\
\hline $4 \% \mathrm{Cr}-\mathrm{Mo}$ steel & 0.90 & 0.60 & 0.31 & 0.013 & 0.009 & 4.17 & 0.34 & - & - & Forged \& spheroidized & $\begin{array}{l}920^{\circ} \mathrm{C} \times 1 \mathrm{hr} \rightarrow \mathrm{Oil}, \\
150^{\circ} \mathrm{C} \times 5 \mathrm{hr} \rightarrow \mathrm{FC}\end{array}$ \\
\hline $5 \% \mathrm{Cr}-\mathrm{Mo}$ steel & 0.89 & 0.52 & 0.25 & 0.011 & 0.008 & 5.00 & 0.34 & & - & Forged \& spheroidized & $\begin{array}{l}920^{\circ} \mathrm{C} \times 1 \mathrm{hr} \rightarrow \mathrm{Oil}, \\
150^{\circ} \mathrm{C} \times 5 \mathrm{hr} \rightarrow \mathrm{FC}\end{array}$ \\
\hline $\begin{array}{l}\text { 1. } 5 \mathrm{Mn}-1.5 \% \mathrm{Cr}-\mathrm{Mo} \\
\text { steel }\end{array}$ & 0.82 & 0.61 & 1.56 & 0.028 & 0.005 & 1.87 & 0.28 & - & - & Cast \& spheroidized & $\begin{array}{l}900^{\circ} \mathrm{C} \times 1 \mathrm{hr} \rightarrow \mathrm{Oil}, \\
150^{\circ} \mathrm{C} \times 5 \mathrm{hr} \rightarrow \mathrm{FC}\end{array}$ \\
\hline $12 \% \mathrm{Cr}-\mathrm{Mo}-\mathrm{V}-\mathrm{Co}$ steel & 1.62 & 0.24 & 0.32 & 0.019 & 0.021 & 12.3 & 0.82 & 0.57 & 0.64 & Forged \& spheroidized & $\begin{aligned} 1050^{\circ} \mathrm{C} \times 1 \mathrm{hr} & \rightarrow \mathrm{Oil}, \\
150^{\circ} \mathrm{C} \times 5 \mathrm{hr} & \rightarrow \mathrm{FC}\end{aligned}$ \\
\hline
\end{tabular}

subjected to such heat treatment as indicated in Table 1 and it was put to the test in as-quenched condition. When an observation is made on the surface of a tested specimen, Photo. 2 (a), and on the cross-sectional surface $\mathrm{A}-\mathrm{A}^{\prime}$ at the center of specimen located in the rubbed surface, Photo. 2 (b), it is noticed that the crack occurred at a right angle to the rubbing direction and propagated to the depth of about $8 \mathrm{~mm}$.

Photograph 3 shows an enlarged view of the abovementioned crack as etched with $5 \%$ nital, where a rehardened layer due to friction heat is observed to have occurred from immediately below the rubbed surface to the maximum depth of about $0.4 \mathrm{~mm}$, accompanied by a neighbouring heat affected zone, that is, a tempered layer. Figure 2 shows hardness distribution at the center of the cross-sectional surface as shown by Photo. 3, and from this it is inferred that the tempered layer including the re-hardened layer only reaches about $5 \mathrm{~mm}$ deep. And the crack shows a tendency to go beyond the tempered layer. Although the number and depth of the cracks in the rubbed surface of the test specimen vary according to the kind of steel and testing condition, the sensitivity to a thermal shock of a test specimen or the degree of a damage incurred by the specimen can be estimated quantitatively by means of a comparison among the depths of cracks appearing in the cross-sectional surfaces of test specimens.

Further, as regards the temperature of a test specimen as being tested, it is inferred from the distribution of hardness in the cross section of the specimen that the rubbed area of the specimen has been heated locally up to at least $850^{\circ} \mathrm{C}$ due to friction and that a sharp temperature gradient of $500^{\circ} \mathrm{C} / \mathrm{mm}$ or more has taken place in the specimen's surface layer or within the range from the rubbed surface till the depth of $1 \mathrm{~mm}$. This is considered to prove the superiority of this device for thermal shock testing.

\section{Influence of Friction Time, Load, and Specimen Thick- ness on the Depth of Crack}

The testing device was evaluated to be good enough as to provide a reproduction of a thermal shock crack formed in the surface of a roll. However, it is necessary to know in advance influences of such factors as friction time, load, and thickness of specimen on crack formation, to determine quantitatively the sensitivity

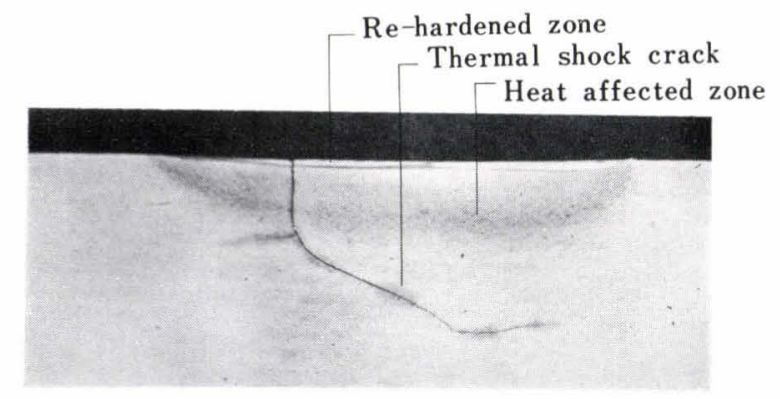

Photo. 3. Structure of center section of the same specimen as shown in Photo. 2

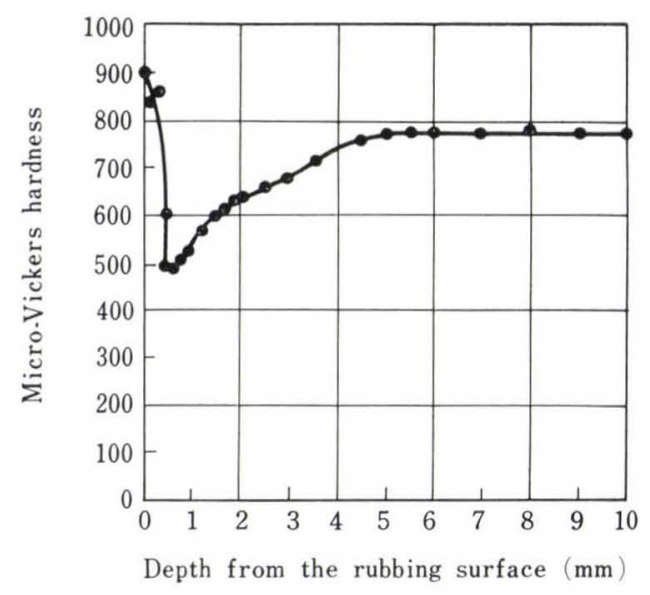

Fig. 2. Hardness distribution along the depth of center section in $2 \% \mathrm{Cr}-\mathrm{Mo}$ steel specimen tested

Table 2. Standard test condition

$\begin{array}{ll}\text { Size of specimen } & \begin{array}{c}\text { Thickness : } 30 \mathrm{~mm}, \text { width : } 60 \mathrm{~mm}, \\ \text { length : } 80 \mathrm{~mm}\end{array} \\ \begin{array}{ll}\text { Size of rotating disc } & \text { Thickness : } 30 \mathrm{~mm} \text {, diameter : } 550 \mathrm{~mm} \\ \text { Revolution of disc } & 1040 \mathrm{rpm}\end{array} \\ \begin{array}{l}\text { Counter weight } \\ \begin{array}{l}\text { Load between disc and } \\ \text { specimen }\end{array}\end{array} \\ \begin{array}{l}\text { Loading (testing) time } \\ \text { L }\end{array}\end{array}$

to cracking which depends on the composition of steel and heat treatment. An investigation was made into those influences using a $2 \% \mathrm{Cr}-\mathrm{Mo}$ steel based on a standard condition as listed in Table 2. 


\section{Influence of Friction Time}

Among the above-mentioned factors, only the friction time was varied in this test. Figure 3 shows the length of wear on the surface and the depth of cracks formed in the cross sections of the specimens; it is noticed that the length of wear shows a tendency to increase almost linearly as a function of friction time, while the depth of cracks shows a sharp increase in $5 \mathrm{sec}$ but thereafter tends to saturate without a great change even up to the friction time of $10 \mathrm{sec}$.

\section{Influence of Loads}

Figure 4 shows the influence of the weight on the
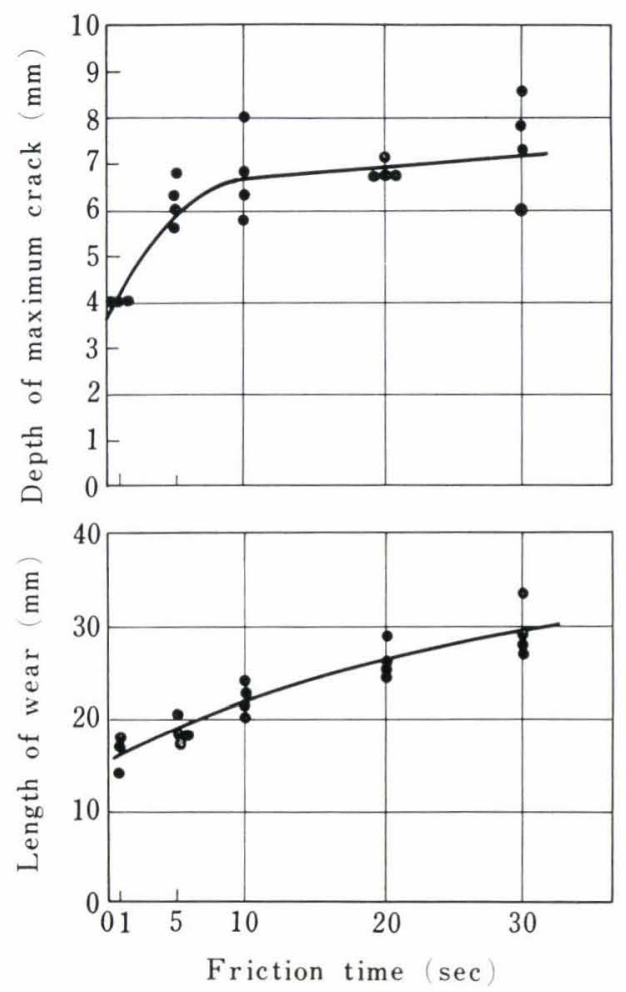

Fig. 3. Influence of friction time on depth of maximum crack in $2 \% \mathrm{Cr}-$ Mo steel specimen tested
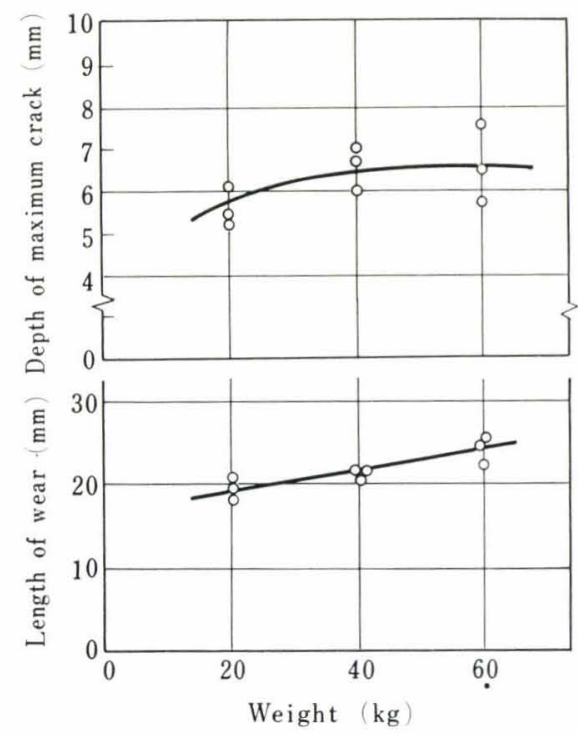

Fig. 4. Influence of test weight on depth of maximum crack in $2 \% \mathrm{Cr}-\mathrm{Mo}$ steel specimen tested end of the cantilever. In this test a similar tendency as the influence of friction time was observed. The length of wear shows an almost linear increase with the increase of load, while the depth of cracks become deeper as the load is increased to $40 \mathrm{~kg}$, but thereafter it shows an inclination to saturate to a certain depth.

\section{Influence of Thickness of Test Specimen}

Only the thickness of test specimens were varied under the condition of constant friction time and load. The result, Fig. 5, proved clearly that, being different from the other cases, the depth of cracks tended to become deeper with the increase of specimen thickness, while no effect was noticed on the length of wear. It is construed that this was caused by restraints of thermal strains during the test which became severer with the increase of specimen thickness. It can be said, therefore, that the larger the thickness of specimen, the better it would be for the purpose of producing thermal shock cracks with ease.

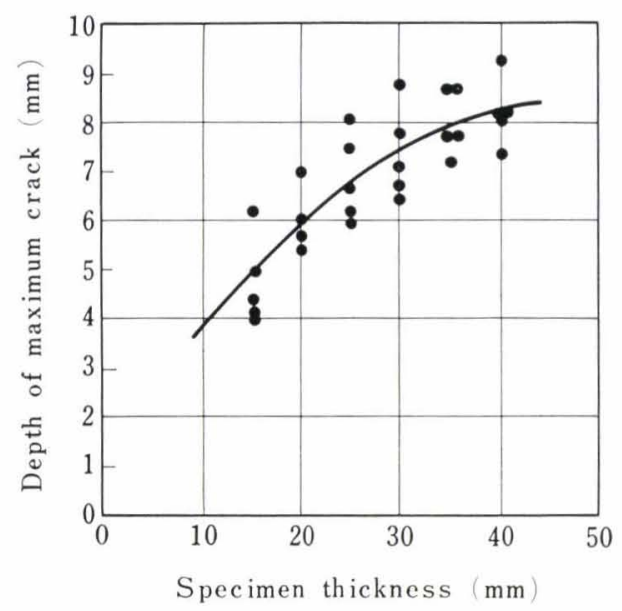

Fig. 5. Influence of specimen thickness on depth of maximum crack in $2 \% \mathrm{Cr}-\mathrm{Mo}$ steel specimen tested

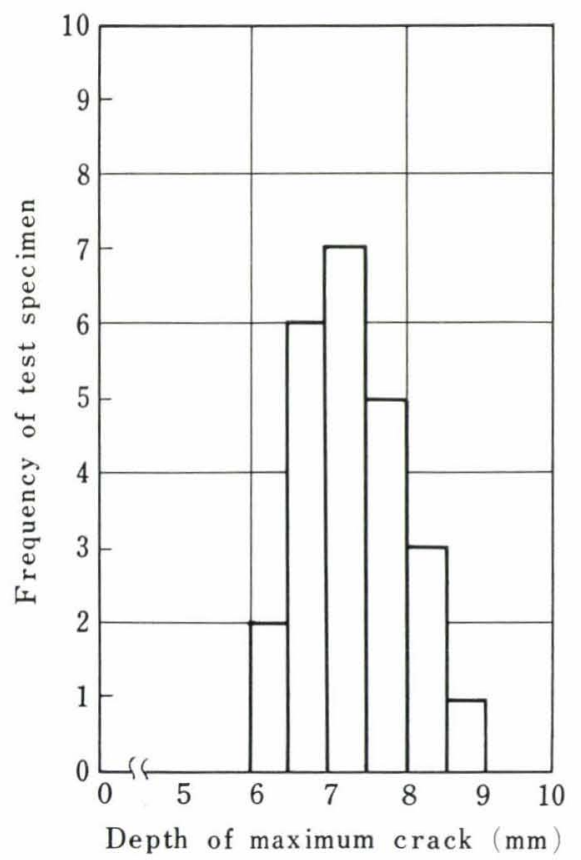

Fig. 6. Distribution of the test result on the $2 \% \mathrm{Cr}-\mathrm{Mo}$ steel specimens 


\section{Standard Test Condition and Reproducibility}

It has been confirmed possible to determine quantitatively the sensitivity of roll materials to the cracking by using the above testing device. However, it is also necessary to have a good understanding on the reproducibility of test results before testing is actually done on a variety of specimens. For this reason tests were made on 24 pieces of specimen of $2 \% \mathrm{Cr}-\mathrm{Mo}$ steel in Table 1 and under the test condition in Table 2. The reason for having chosen the condition of loading for $10 \mathrm{sec}$ by a $60 \mathrm{~kg}$ weight was that small deviations from these requirements would not cause a big variation in the depth of cracks. Another reason was that the thickness of $30 \mathrm{~mm}$ would be within the range to assure the easy occurrence of cracks and easy adjustment of specimens.

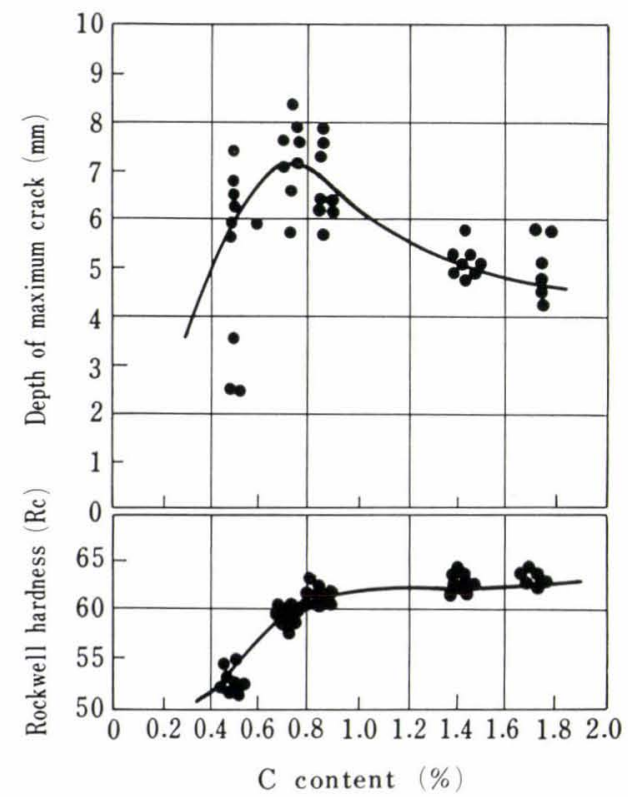

Fig. 7. Influence of carbon content on depth of maximum crack of the $3 \% \mathrm{Cr}-\mathrm{Mo}$ steel

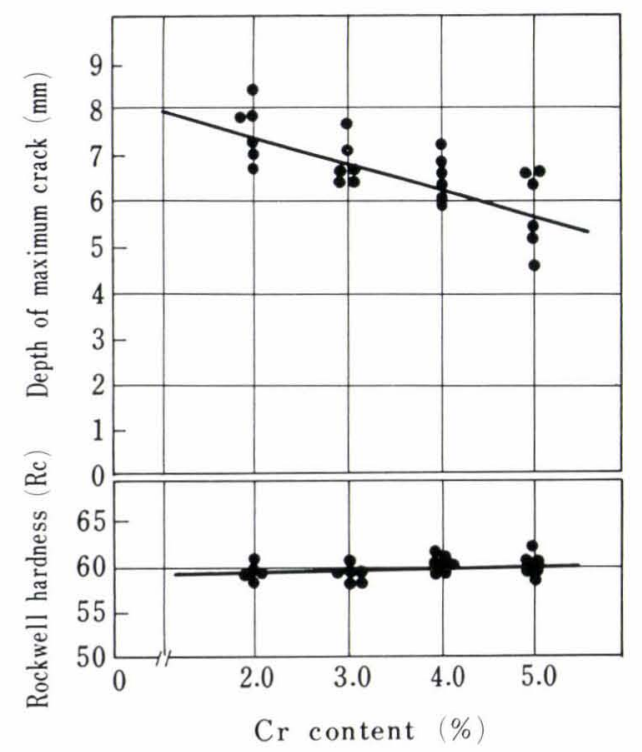

Fig. 8. Influence of chromium content on depth of maximum crack of the $\mathrm{Cr}-\mathrm{Mo}$ steel
Figure 6 shows the relation between crack depth and the frequency; the mean value of maximum depth is $7.27 \mathrm{~mm}$ with a standard deviation of $0.62 \mathrm{~mm}$. Since the deviation is as small as such, it is considered that for industrial purposes this test method can give quantitative evaluations of various specimens. In the following section the above standard test condition was used.

\section{Factors in the Manufacture of Rolls and Thermal Shock Cracking Properties}

\section{Influences of Forging and Annealing Processes}

Forging ratio of up to 3 and the direction of specimen regarding the axis of forging had the effect on the depth of surface cracks formed by testing $2 \% \mathrm{Cr}-\mathrm{Mo}$ and $3 \% \mathrm{Cr}-\mathrm{Mo}$ steels in Table 1 . Further, annealing structures gave scarcely any effect.

Therefore, in the following section, materials forged at a forging ratio 3 and spheroidized were used and

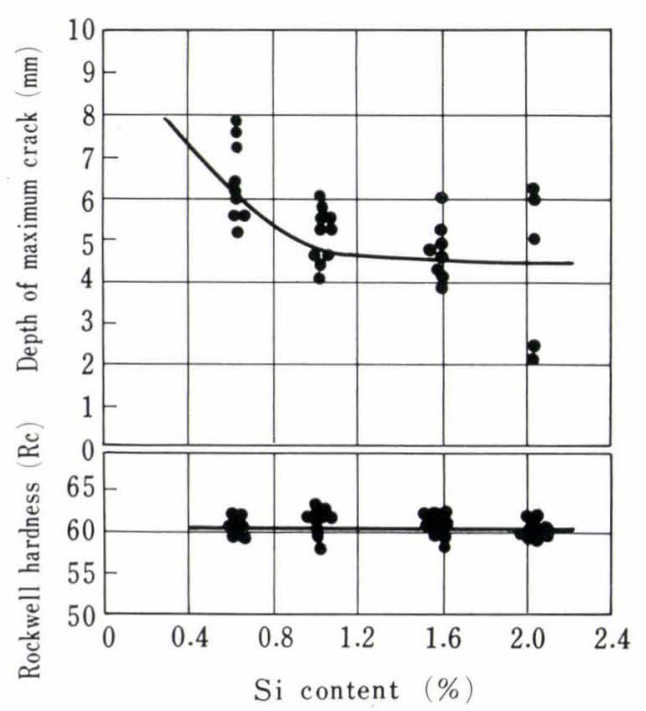

Fig. 9. Influence of silicon content on depth of maximum crack of the $3 \% \mathrm{Cr}-$ Mo steel

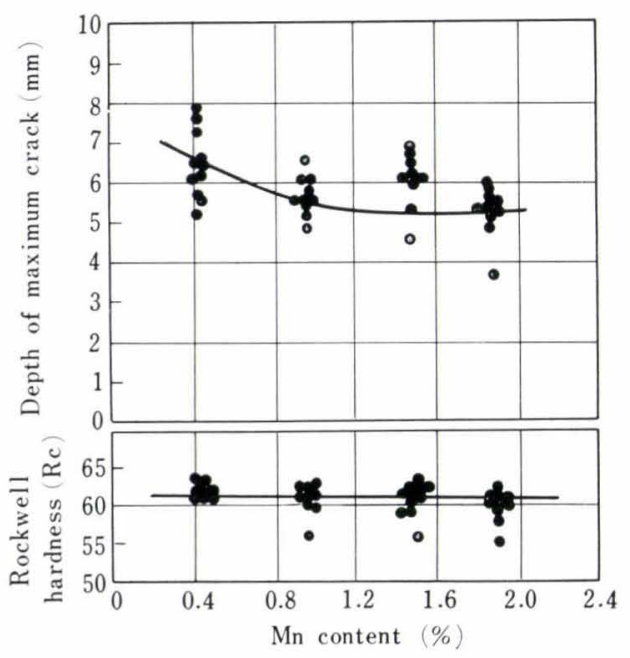

Fig. 10. Influence of manganese content on depth of maximum crack of the $3 \% \mathrm{Cr}-$ Mo steel 
specimens were obtained along the forging axis.

\section{Influence of Chemical Composition}

In order to find out the influence of major chemical elements of roll material the tests were made on the specimens of steels based on the standard $3 \% \mathrm{Cr}-\mathrm{Mo}$ steel of Table 1 and modified for carbon in the range of 0.4 to $1.8 \%$, for chromium 2 to $5 \%$, for silicon 0.6 to $2.0 \%$, or for manganese 0.5 to $1.9 \%$.

Figures 7 through 10 show the test results as summarized below. Carbon: hardness shows a sharp rise with the increase of carbon content up to $0.8 \%$, but scarcely any more rise with further increase of carbon above $0.8 \%$. The depth of thermal shock cracks does not coincide with the hardness change; it shows a tendency to increase as carbon content becomes higher, reaches the maximum at 0.7 to $0.8 \%$ carbon and then decreases with further increase of carbon. It follows from this that carbon contents lower or higher than 0.7 to $0.8 \%$ should be chosen to reduce the depth of cracks owing to thermal shock. In reality, however, rolls need a resistance to wear and other properties as well as the resistance to thermal shock. Since the rolls with high hardness values are demanded in general, the roll materials of higher carbon content will naturally be selected from the above two points.

Chromium: when a high hardness value is aimed by increasing the content of chromium, the quenching temperature must be somewhat elevated. However, the depth of cracks decreases as the chromium content increases; there is essentially a linear relation between them. Therefore the higher the chromium content, the better the quality of the roll will be.

Silicon and manganese: as the contents of silicon and manganese become higher, the depth of cracks shows a tendency to decrease gradually up to about $1 \%$, although little change is recognized in hardness.

According to the findings as mentioned above, it has been clarified that by the change of chemical compositions a great influence can be exerted on the depth of thermal shock cracks. In this experiment, however, each element was increased or decreased independently and complicated interactions of several elements remain to be an important subject to be studied.

\section{Influence of Heat Treatment}

It has been made clear that scarcely any influence is noticed on the cracks by changing annealed structures. However, since the quenching and tempering temperatures had a noticeable effect on the major properties of a roll, an investigation was made in this regard.

\section{Influence of Austenitizing Temperature}

Specimens of $2 \% \mathrm{Cr}-\mathrm{Mo}$ and $1.5 \% \mathrm{Mn}-1.5 \% \mathrm{Cr}$ steels with quenching temperatures modified from Table 1 were tested, the result being shown in Fig. 11.

A clear difference exists in the processes of cracking of the two steels : $1.5 \% \mathrm{Mn}-1.5 \% \mathrm{Cr}$ steel shows an increase in the depth of cracks with the rise of austenitizing temperature, while in case of $2 \% \mathrm{Cr}-\mathrm{Mo}$ steel the depth reaches the maximum at $840^{\circ} \mathrm{C}$, tending to become gradually smaller thereafter with the further rise

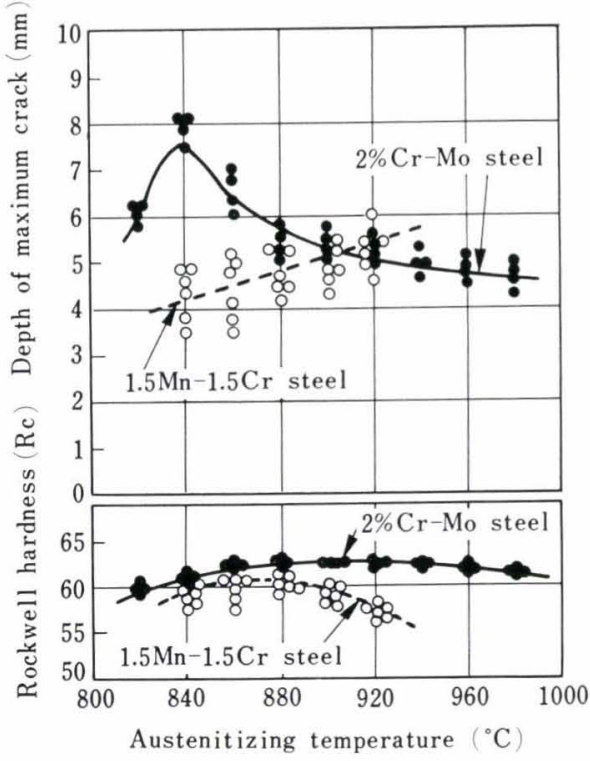

Fig. 11. Influence of austenitizing temperature on depth of maximum crack of the $2 \% \mathrm{Cr}-\mathrm{Mo}$ steel and the $1.5 \mathrm{Mn}-1.5 \mathrm{Cr}$ steel

of austenitizing temperature. In respect to the hardness of $2 \% \mathrm{Cr}-\mathrm{Mo}$ steel, meanwhile, a great variation was not made by austenitizing temperatures. As the hardness reaches its maximum at the austenitizing temperature around $900^{\circ} \mathrm{C}$, it is possible to reduce the depth of thermal shock cracks with high hardness values by selecting a proper austenitizing temperature. ${ }^{19)}$

Considering that a relation between austenitizing temperature and crack depth depends on the kind of steel, it is deemed very important to grasp the properties relating to the cracks as well as other properties of roll materials, when a research is to be made aiming at the development of such rolls as most unlikely to incur damages by thermal shock cracks.

\section{Influence of Tempering Temperature}

It is generally said that the higher the tempering temperature ${ }^{10)}$ the more unlikely thermal shock cracks are to occur, and consequently an investigation was made with specimens of $3 \% \mathrm{Cr}-\mathrm{Mo}$ and $12 \% \mathrm{Cr}-\mathrm{Mo}-$ $\mathrm{V}$-Co steels in Table 1, by varying only tempering temperatures.

As shown in Fig. 12, hardness of 3\% Cr-Mo steel gradually decreased with the rise of tempering temperature and the maximum depth of cracks became smaller at the same time, showing the result as generally understood. In case of $12 \% \mathrm{Cr}-\mathrm{Mo}-\mathrm{V}-\mathrm{Co}$ steel, on the other hand, the crack depth reduced as the rise of tempering temperature but turned to increase beyond $450^{\circ} \mathrm{C}$. From the relation between tempering temperature and hardness, it is considered that secondary hardening phenomenon took place in this case. It is also considered that this behaviour of $12 \% \mathrm{Cr}-\mathrm{Mo}-\mathrm{V}-$ Co steel resulted from a combined effect of the decrease of crack depth due to softening by tempering and the increase of crack depth due to the secondary hardening, but this cannot be affirmed positively, as 


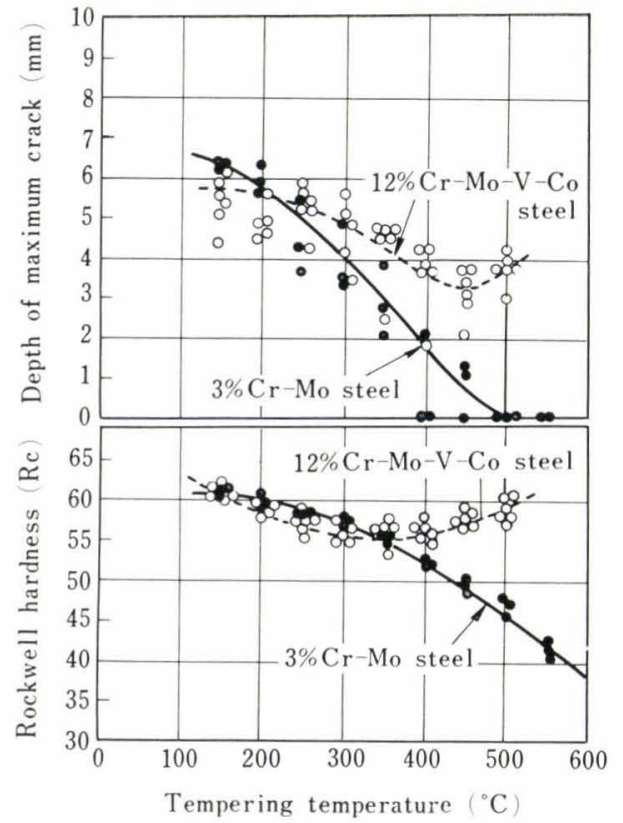

Fig. 12. Influence of tempering temperature on depth of maximum crack of the $3 \% \mathrm{Cr}-\mathrm{Mo}$ steel and the $12 \% \mathrm{Cr}-\mathrm{Mo}-\mathrm{V}$-Co steel

the hardness increase due to the secondary hardening is not in a perfect agreement with the tendency of crack depth. In this steel, anyway, it is possible to determine a tempering temperature most appropriate to minimize the damage of thermal shock cracks while aiming at the same hardness.

\section{Some Considerations on the Factors that Influence Ther- mal Shock Cracking}

A number of factors can be taken up to influence the depth of thermal shock cracks, and they are considered to govern the depth of cracks independently or interrelatedly, but the examination was made merely from the phenomenological viewpoint of a few factors which might influence the depth of cracks, and the study has not reached the step where the mechanisms ruling the formation of cracks or the depth of cracks can be described. However, since it can be easily imagined that such factors as thermal shock on material surface, thermal stress due to cooling, transformation property, structures, and strength are major ones that influence the depth of cracks, a few considerations were made on these points as follows.

The formation of a re-hardened layer depends on whether the maximum temperature on the surface of a steel exceeds the $\mathrm{Ac}_{1}$ transformation point or not, and even if it forms, its depth is relatively very small as compared with the tempered layer as seen in Photo. 3 , accordingly it can be considered that the properties of this tempered layer may exert a direct effect on the cracks. A large amount of residual tensile stress was observed in this tempered layer. With the test specimens $5 \mathrm{~mm}$ in diameter and $70 \mathrm{~mm}$ in length of $2 \% \mathrm{Cr}-$ Mo, 3\% Cr-Mo, and 5\% Cr-Mo steels which had been subjected to the standard heat treatment as in Table 1, an investigation was made to measure the variation of

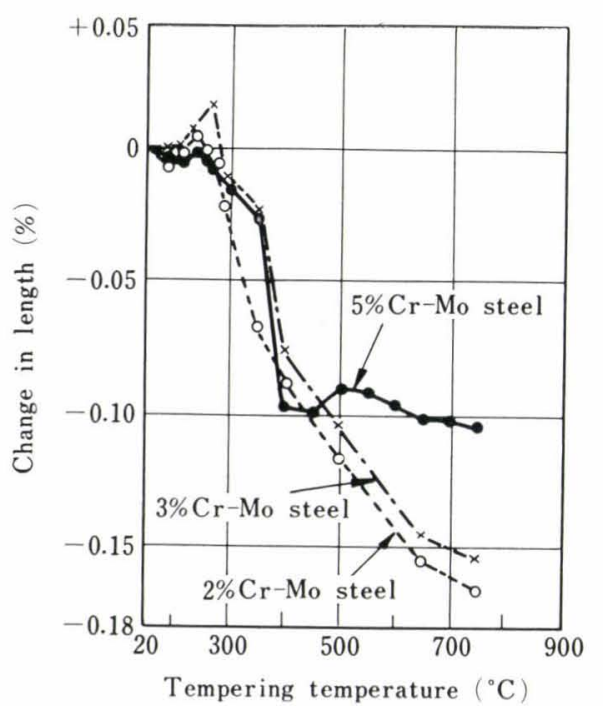

Fig. 13. Relation between tempering temperature and change in length of three steels

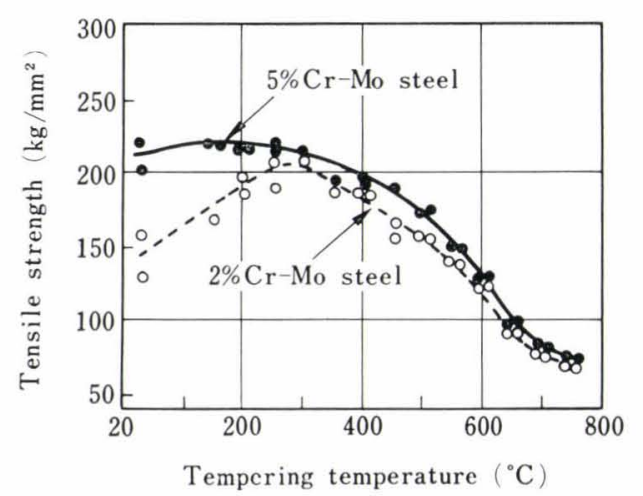

Fig. 14. Tensile strength of two steels tested after tempering

length after being heated for two hours at various temperatures up to $750^{\circ} \mathrm{C}$. As seen in Fig. 13, contractions in length took place, in the course of change from martensite to sorbite, suggesting that it can induce the tensile stresses that cause the cracks. Further, by comparing these three steels, it was found that the smaller contraction took place the higher the chromium content except when tempering temperature was lower than $300^{\circ} \mathrm{C}$, and it was also found that the maximum depth of cracks reduced as the chromium content increased as seen in Fig. 8. From these findings, it can be said that the formation of the cracks is influenced by the contraction of volume in tempering process and is a function of the contents of alloying elements.

At the same time it is considered that the property of the material of the part where a crack appears ought to have some influence on the formation of the crack. Therefore an examination was made to compare the tensile strength of $2 \% \mathrm{Cr}-\mathrm{Mo}$ steel with that of $5 \% \mathrm{Cr}-$ Mo steel tempered at some temperatures where thermal shock is expected to occur. In Fig. 14, 5\% CrMo steel possesses a higher tensile strength, showing a remarkable difference in the region of low temperatures below $300^{\circ} \mathrm{C}$ in particular. It can be said that the 


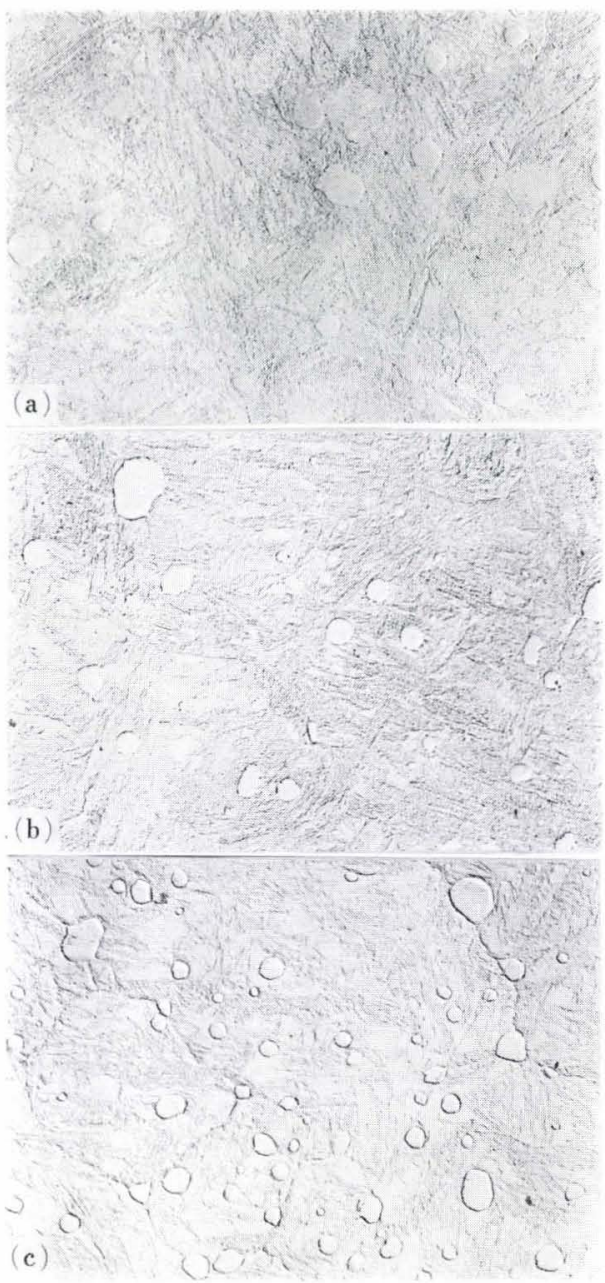
(a) $2 \% \mathrm{Cr}-\mathrm{Mo}$ steel
(b) $3 \% \mathrm{Cr}-\mathrm{Mo}$ steel

(c) $5 \% \mathrm{Cr}-\mathrm{Mo}$ steel

Photo. 4. Electron microstructures in surface layer of the cold work rolls

increase of chromium content reduces the tensile stress originating in thermal shock, while increasing the strength to resist the formation of cracks. Also about the depth of cracks, it is natural to consider that the property of material as to crack propagation or property as to the arresting of crack propagation has some influence, but there are many points which are uncertain at the present stage.

Further to mention, it is a general tendency for a high carbon steel such as used in this study that mechanical properties such as tensile strength becomes degraded when its hardening temperature exceeds a certain point, while in case of $2 \% \mathrm{Cr}-\mathrm{Mo}$ steel a different tendency was observed, i.e., the depth of cracks decreased as its austenitizing temperature became higher than $840^{\circ} \mathrm{C}$, as seen in Fig. 11. In Photo. 4, every test specimen used had a structure of martensite with fine residual carbides distributed, alloying elements being contained in both of the matrix and carbides. Carbon and chromium contents in the matrix were calculated through the analysis of carbides. The result as shown in Table 3 reveals that the amount of chromium contained in matrix becomes greater as chromium content of steel is increased. As it has
Table 3. Carbon and chromium contents in the matrix

\begin{tabular}{ccc} 
Material & $\mathrm{C}(\%)$ & $\mathrm{Cr}(\%)$ \\
\hline $2 \%$ Cr-Mo steel & 0.54 & 1.56 \\
$3 \%$ Cr-Mo steel & 0.55 & 1.68 \\
$5 \%$ Cr-Mo steel & 0.53 & 3.17 \\
\hline
\end{tabular}

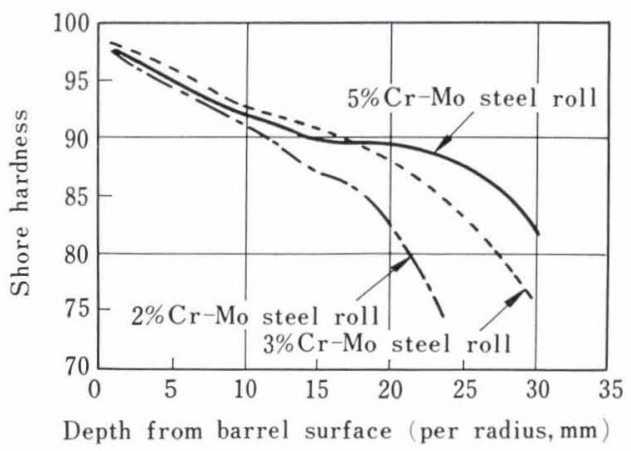

Fig. 15. Hardness penetration curves of the rolls

already been clarified that the depth of cracks are reduced as the chromium content of a steel increases, and carbides themselves are not considered to have a great influence on the depth of cracks, it is deemed that the chromium content in the matrix must have exerted a great effect on the depth of cracks. In case of $2 \% \mathrm{Cr}-$ Mo steel in Fig. 11, it is inferred that the depth of thermal shock crack were reduced, as the result of chromium content in matrix becoming higher owing to the elevation of austenitizing temperature. Therefore, this suggests the possibility that a new type of roll with superior property to resist thermal shock cracks may be developed by a study as to what influence is effected on the property of material relating to the occurrence and propagation of cracks by alloying elements and their amount contained in the matrix of material.

\section{Development of Crack Resisting Roll}

The most appropriate measures to mitigate the damages due to thermal shock cracks were confirmed to be the modifications of composition of steel and heat treatment through the present experiment. Rolls of $3 \% \mathrm{Cr}-\mathrm{Mo}$ and 5\% Cr-Mo steel in Table 1 were manufactured and put to an actual mill service, and such a performance record as evidencing the results of the above-mentioned experiment was obtained.

Of these rolls the microstructure and hardness penetration are shown in Photo. 4 and Fig. 15; it is seen that the hardness penetration is improved in comparison with the conventional $2 \% \mathrm{Cr}-\mathrm{Mo}$ steel roll, and especially in the case of $5 \% \mathrm{Cr}$-Mo steel roll the hardness is lowered very slightly within the range of 15 to $20 \mathrm{~mm}$ from the surface. It is further noticed that the amounts of residual carbides in the hardened surface layer increase in the order of $2 \% \mathrm{Cr}-\mathrm{Mo}, 3 \% \mathrm{Cr}-$ $\mathrm{Mo}$, and 5\% $\mathrm{Cr}-\mathrm{Mo}$ steels and that the martensite structures of the matrix become finer in this order. This is considered to indicate the improvement of such 
Table 4. Performance data of the work roll in the cold strip mills

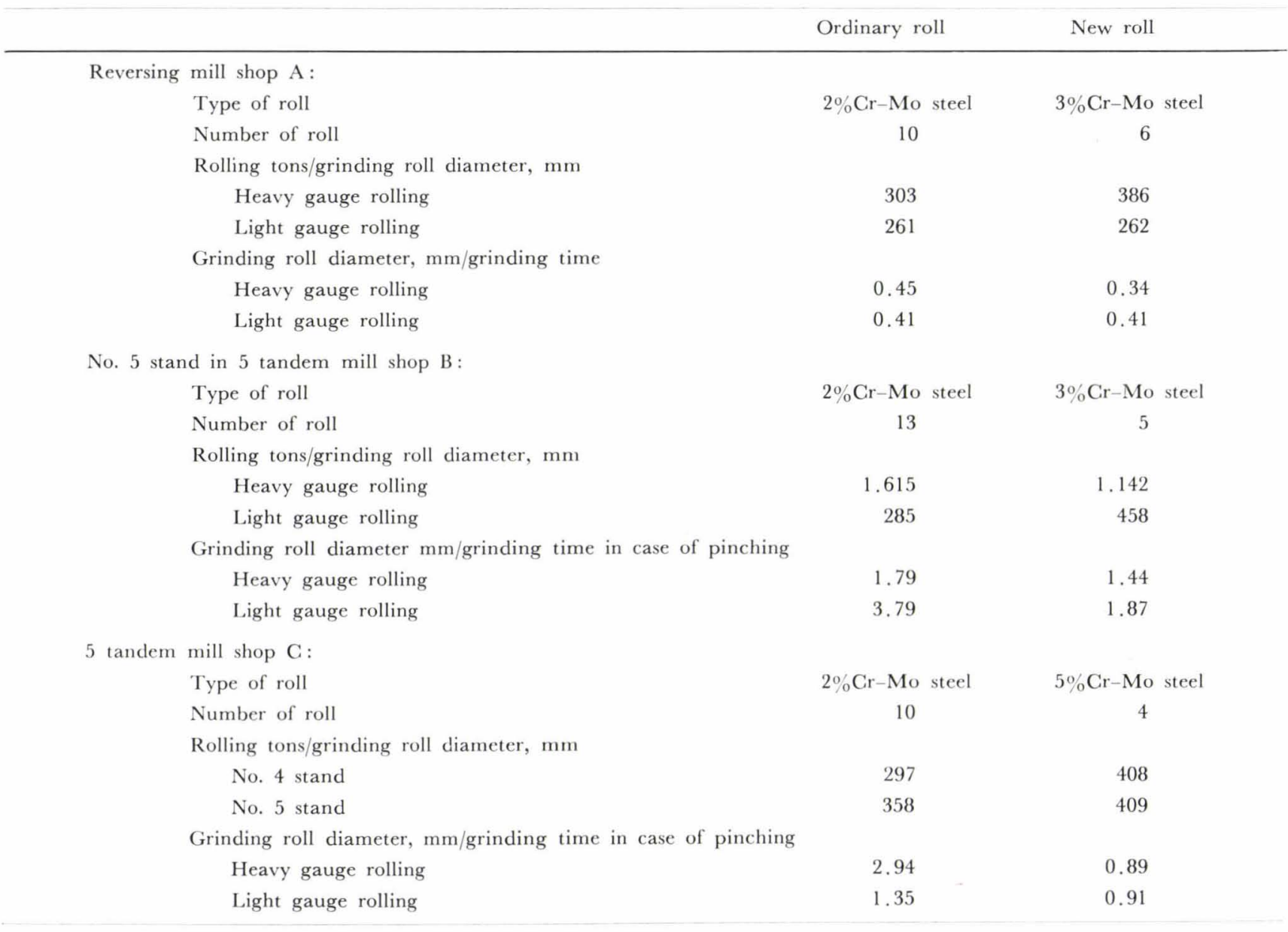

properties as resistance to wear, which are requisite for rolls.

Table 4 shows a performance data of work rolls in mill shops. The rolls in this data were selected at randam from those put to service on the respective mills during the same period of time. The newly developed rolls of $5 \% \mathrm{Cr}-\mathrm{Mo}$ and $3 \% \mathrm{Cr}-\mathrm{Mo}$ steels with high resistance to thermal shock cracks give good performance results as seen in the table. Especially the amount of surface grinding of the roll of $5 \% \mathrm{Cr}-\mathrm{Mo}$ steel is only half or one-third those of conventional type rolls per one pinching trouble. This means that the depth of maximum cracks by pinching trouble has been reduced to half or one-third those of conventional type rolls, with a remarkable improvement in the total rolled tonnage per a unit depth of surface grinding.

\section{Conclusions}

(1) A thermal shock testing device of the type using the friction of rotary disc was made to simulate the cracking on the surface of cold mill work rolls by thermal shock due to rolling troubles such as slipping, pinching and crumpling, burning, etc. This testing device enabled a quantitative comparison with ease by measuring the depth of cracks, showing many advantages over the qualitative testing methods em- ployed so far when such phenomena as burning and cracking are the subject of investigation.

(2) Details of the mechanism determining the conditions to form the cracks and their depth have not been made clear at present stage and this remains to be a subject for study in the future. Some of the factors such as compositions and heat treating conditions which influence the depth of cracks were revealed to a certain extent.

(3) Chemical compositions, especially, exerted a substantial influence on the depth of cracks and a remarkable effect was noticed on the chromium content in particular. The depth of cracks decreased according to the increase of chromium content and this was considered attributable to the facts that the strength of martensite matrix is increased in the temperature range where thermal shock occurs and that the change of volume at the time of change from martensite to sorbite is made smaller.

(4) Rolls of 3\% Cr-Mo and 5\% Cr-Mo steels whose chromium contents were higher than those of ordinary 1 to $2 \% \mathrm{Cr}-\mathrm{Mo}$ steels were manufactured according to the present test results and put to test service on mills. As the result, it was confirmed that they were improved in quality especially in their property to resist thermal shock cracks. 


\section{REFERENCES}

1) K. Sakabe and T. Sibazaki: Japan Steel Works Technical Review, (1966), No. 12, 31.

2) K. Hori, U. Arakida, and H. Tabe: Tetsu-to-Hagané, 51 (1965), 2004.

3) K. Hori, U. Arakida, and H. Tabe: J. Japan Soc. Technology of Plasticity, 8 (1967), No. 76, 261.

4) K. Kudo: Japan Steel Works Technical Review, (1960), No. 26,43 .

5) W. E. Littman and J. W. Wulf: Amer. Soc. Metals, 47 (1955), 692.

6) M. Matsui, Y. Honda, and R. Setoguchi: J. Japan Soc. of Precision Engineering, 31 (1965), No. 12, 996.

7) K. Ono: Research Reports of Factory of Engineering of Niigata Univ., 6 (1957), 123.

8) T. Takasawa and Y. Yokoyama: Spring Meeting Preprint II, The Japan Soc. of Precision Eng., (1956), 43.

9) K. Ogawa and K. Ono: J. Japan Inst. Metals, 19 (1954),
33.

10) K. Monma: Tetsu-to-Hagané, 22 (1936), 425.

11) K. Sato, H. Takeuchi, K. Miura, and S. Sakashita: J. Japan Soc. Technology of Plasticity, 10 (1969), No. 101, 405.

12) H. Tabe, T. Yamashita, and K. Hori: Tetsu-to-Hagané, 55 (1969), S583.

13) T. Shimeji and H. Ozawa: Tetsu-to-Hagané, 41 (1955), 341 .

14) H. Tabe: Japan Steel Works Technical Review, (1965), No. 20, 18.

15) H. Shimoda, K. Sakabe, U. Arakida, and H. Matsuo: Tetsu-to-Hagané, 52 (1966), 667.

16) J. Watanabe, T. Shibazaki, and Y. Kumada: Japan Steel Works Technical Review, (1962), No. 9, 47.

17) H. Hori, U. Arakida, and H. Tabe: Tetsu-to-Hagané, 52 (1966), 639.

18) H. Tabe and H. Hori: Tetsu-to-Hagané, 56 (1970), S138.

19) H. Tabe and H. Hori: Tetsu-to-Hagané, 55 (1969), S583. 